\title{
Domestic Safeguards Material Control and Accountancy Considerations for Molten Salt Reactors
}

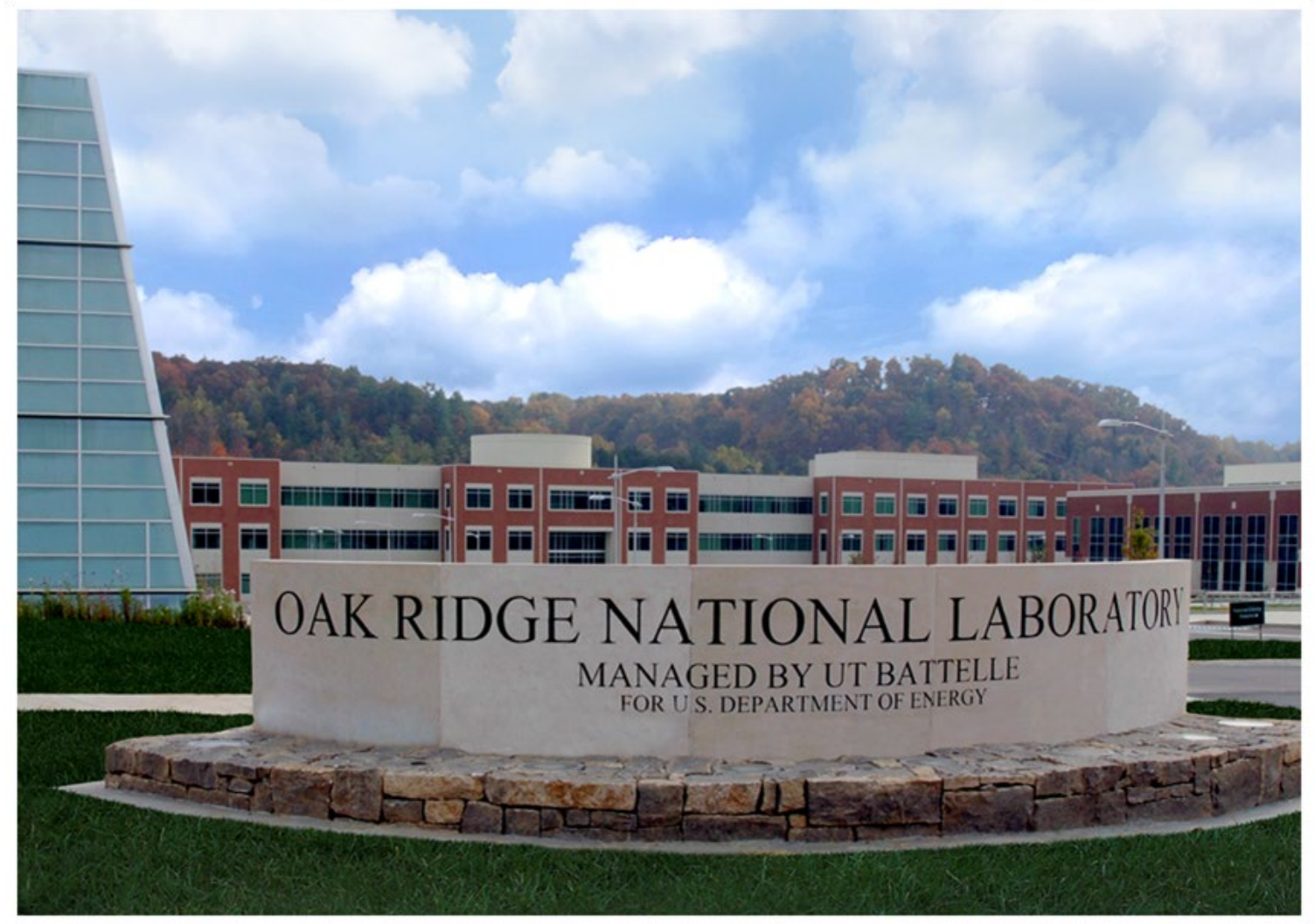

Karen K. Hogue Philip Gibbs Michael P. Dion Mike Poore

February 2021 


\title{
DOCUMENT AVAILABILITY
}

Reports produced after January 1, 1996, are generally available free via US Department of Energy (DOE) SciTech Connect.

Website www.osti.gov

Reports produced before January 1, 1996, may be purchased by members of the public from the following source:

\author{
National Technical Information Service \\ 5285 Port Royal Road \\ Springfield, VA 22161 \\ Telephone 703-605-6000 (1-800-553-6847) \\ TDD 703-487-4639 \\ Fax 703-605-6900 \\ E-mail info@ntis.gov \\ Website http://classic.ntis.gov/
}

Reports are available to DOE employees, DOE contractors, Energy Technology Data Exchange representatives, and International Nuclear Information System representatives from the following source:

Office of Scientific and Technical Information

PO Box 62

Oak Ridge, TN 37831

Telephone 865-576-8401

Fax 865-576-5728

E-mail reports@osti.gov

Website http://www.osti.gov/contact.html

This report was prepared as an account of work sponsored by an agency of the United States Government. Neither the United States Government nor any agency thereof, nor any of their employees, makes any warranty, express or implied, or assumes any legal liability or responsibility for the accuracy, completeness, or usefulness of any information, apparatus, product, or process disclosed, or represents that its use would not infringe privately owned rights. Reference herein to any specific commercial product, process, or service by trade name, trademark, manufacturer, or otherwise, does not necessarily constitute or imply its endorsement, recommendation, or favoring by the United States Government or any agency thereof. The views and opinions of authors expressed herein do not necessarily state or reflect those of the United States Government or any agency thereof. 
National Security Sciences Directorate

\title{
DOMESTIC SAFEGUARDS MATERIAL CONTROL AND ACCOUNTANCY CONSIDERATIONS FOR MOLTEN SALT REACTORS
}

\author{
Karen K. Hogue \\ Philip Gibbs \\ Michael P. Dion \\ Mike Poore
}

February 2021

Prepared by

OAK RIDGE NATIONAL LABORATORY

Oak Ridge, TN 37831-6283

managed by

UT-BATTELLE, LLC

for the

US DEPARTMENT OF ENERGY

under contract DE-AC05-00OR22725 



\section{CONTENTS}

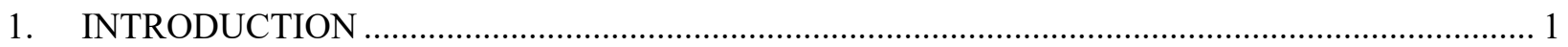

2. APPLICABILITY OF NRC REGULATIONS TO MSRs …................................................. 2

3. MSR DESIGN FEATURES THAT ARE RELEVANT TO MC\&A …....................................... 4

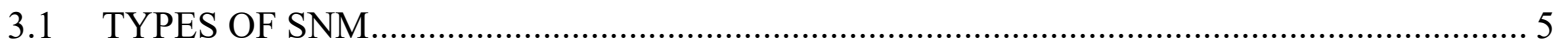

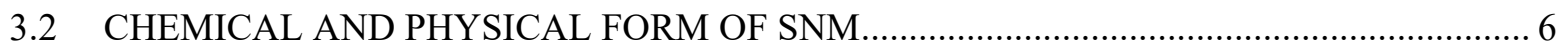

3.2.1 Radioactivity of material in which the SNM is located .......................................... 7

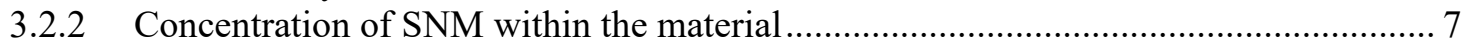

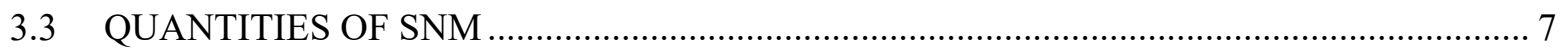

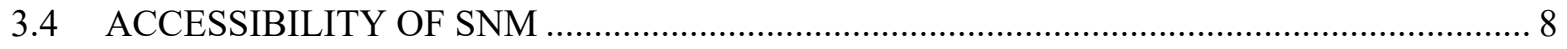

4. POTENTIAL MC\&A CHALLENGES AND RECOMMENDATIONS …..................................... 8

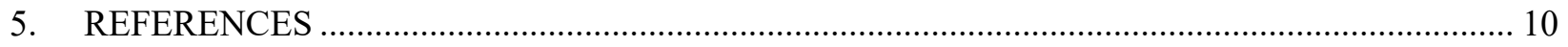




\section{INTRODUCTION}

Molten salt reactors (MSRs) are a class of nuclear reactor designs with features and operational characteristics that vary significantly more than the class of light water reactors (LWRs). MSR design concepts can be broadly categorized as

- $\quad$ solid-fueled reactors with molten salt as the coolant ${ }^{1}$,

- liquid-fueled reactors with fuel dissolved in molten salt coolant ${ }^{2}$, and

- liquid-fueled reactors with fuel dissolved in molten salt that is contained in distinct fuel tubes with a nonfissile coolant ${ }^{3}$.

Proposed MSR concepts include features that are specific to each design. MSR concepts vary widely across these design features, including the physical, chemical, and isotopic composition of fresh and irradiated fuel. Operational neutron energy spectrums and breeding ratios also vary significantly across design concepts. Some concepts are burner reactors designed to transmute the spent nuclear fuel from LWRs or pressurized heavy water reactors (PHWRs) ${ }^{4}$, while others are breeder reactors designed to breed fissile ${ }^{233} \mathrm{U}$ from naturally occurring fertile ${ }^{232} \mathrm{Th}$. Some MSR concepts are designed to be a part of a oncethrough fuel cycle, while others involve chemical separation. Those that include plans to recycle the fuel differ by whether the chemical processing would be done onsite, as a process connected to the fuel salt itself, or offsite at a reprocessing facility similar to how LWR or PHWR spent fuel is reprocessed in some countries. Each overall design concept contains various aspects of each of these features to produce a unique facility.

Because of these broad design variations, the material control and accounting (MC\&A) approaches for this class of reactors will vary significantly. Rather than attempting to categorize MSR designs into MC\&A-relevant categories, the authors recommend identifying design features that will significantly impact MC\&A requirements as they relate to domestic safeguards within this class of reactor designs. This will allow the Nuclear Regulatory Commission (NRC) and designers to identify areas in which a specific designs might face MC\&A challenges. Designers may then address challenges by altering a design feature(s), building in additional security features (to ensure that diversion scenarios associated with those design features are determined to be noncredible), or incorporating in-situ measurement systems to appropriately account for the nuclear material.

Section 2 of this paper assesses the applicability of current NRC MC\&A regulations to the class of MSRs, proposes general approaches that designers might take to meet current NRC requirements, and recommends how the NRC might modify its current requirements to more effectively and efficiently achieve robust MC\&A in MSR designs. Section 3 identifies MC\&A-relevant design features of MSRs and highlights the variations among the MSR designs within each of these design features. Section 4

\footnotetext{
${ }^{1}$ Examples include the Kairos Power (Kairos Power 2020) and Chinese TMSR-SF1 (Hongjie 2017) designs, both of which use tristructural isotropic particle (TRISO) fuel in pebble form.

${ }^{2}$ Examples include Flibe Energy's Liquid Fuel Thorium Reactor (Flibe Energy 2020), TerraPower's Molten Chloride Fast Reactor (TerraPower 2020), Terrestrial Energy's Integral Molten Salt Reactor (Terrestrial Energy 2020), and ThorCon (ThorCon 2020) designs.

${ }^{3}$ An example includes the Moltex Energy Stable Salt Reactor design (Scott 2020).

${ }^{4}$ Moltex Energy's Stable Salt Reactor is designed to burn irradiated Canada deuterium uranium (CANDU) reactor fuel (Scott 2020).
} 
highlights some of the MC\&A challenges of MSRs and recommends potential approaches to address these challenges.

\section{APPLICABILITY OF NRC REGULATIONS TO MSRs}

Title 10 of the Code of Federal Regulations Part 74 (10 CFR Part 74) defines MC\&A requirements for special nuclear material (SNM). MC\&A requirements are defined based on the strategic significance of the SNM. The LWR uranium-based fuel used in US commercial nuclear reactors is less than $10 \%$ enriched in the isotope ${ }^{235} \mathrm{U}^{5}$. Although plutonium exists in LWR spent nuclear fuel ${ }^{6}$, LWR fuel assemblies are large, heavy, and highly radioactive, which significantly decreases the likelihood of diversion scenarios via theft. Because of this, the NRC only requires LWRs to meet the sabotage design basis threat (DBT) and not the theft/diversion DBT. Therefore, in accordance with 10 CFR $\S 74.7$, the NRC's MC\&A regulations for LWR are less stringent and do not require the full implementation of Category I and Category II MC\&A requirements.

SNM in liquid-fueled MSRs with fuel dissolved in molten salt does not have a set physical form (i.e., an "item") that is large and heavy. Irradiated SNM in the salt would have high activities, similar to LWRs. However, some liquid-fueled MSR designs include varying degrees of fuel salt cleanup systems and/or have online chemical separation of fissile material for recycle back into the reactor. Additionally, liquid-fueled MSR designs use off-gas and cover gas management systems to extract the radioactive fission gases from the system. Thus, liquid-fueled MSRs have several radionuclide streams to consider and some of them may have SNM present without accompanying high dose rates ${ }^{7}$. Additionally, unlike LWRs in which the SNM arrives at commercial reactor facilities in the form of large fuel assemblies or bundles and remains in that physical form throughout all processes at the facility, liquid-fueled MSR designs may include fresh fuel arriving at the facility in a concentrated form (to reduce the volume of fresh fuel). Solid-fueled MSR designs with a molten salt coolant and solid TRISO fuel will likely require NRC MC\&A approaches similar to those for pebble-bed reactor designs ${ }^{8}$. Liquid-fueled MSR designs with distinct fuel assemblies and nonfissile coolant would most likely have MC\&A approaches similar to other item facilities, including LWRs, depending on the dimensions of the assemblies. In these cases, measurement systems or reactor code to estimate the SNM quantities within the assemblies filled with salt would likely be proposed.

There are two general categories of MC\&A approaches that may be appropriate for MSRs: a "black box" material-balance approach that could be combined with robust containment and surveillance on the SNM in the reactor itself or an approach that aims to quantify the SNM throughout the reactor. Table 1 briefly describes some of the benefits, challenges, and potential gaps in each of these methodologies. The first "black box" MC\&A approach is similar to LWRs and other facilities where the SNM exists in an accountable physical item. Extrapolating this approach to solid-fueled MSRs in which TRISO fuel pebbles could either individually be accounted for or (more likely) groups of fuel pebbles within a vessel could be accounted for before entering and after exiting the reactor ${ }^{9}$ would be reasonable. This approach

\footnotetext{
${ }^{5}$ Category III, SNM of low strategic significance is defined as 10,000 grams or more of ${ }^{235} \mathrm{U}$ enriched to less than 10\% (Nuclear Regulatory Commission 2017).

${ }^{6}$ The presence of plutonium would typically cause the SNM to be categorized as Category I, strategic SNM (Nuclear Regulatory Commission 2017).

${ }^{7}$ Ongoing research is being conducted in this area to estimate dose rates, isotopic assays, and the SNM concentrations within materials, which would lead to the volume of material and/or the number of containers that would need to be diverted to account for quantities of the SNM of strategic significance.

${ }^{8}$ See (Kovacik, Gibbs and Scott 2020) for additional information related to MC\&A for pebble-bed reactors.

${ }^{9}$ Research from (Kovacik, Gibbs and Scott 2020) describes a similar approach for pebble-bed reactors.
} 
could also be reasonably extrapolated to liquid-fueled MSRs where the fuel is contained in distinct fuel assemblies.

Table 1. Description of two general approaches to MC\&A at MSRs.

\begin{tabular}{|c|c|c|c|c|}
\hline $\begin{array}{c}\text { General MC\&A } \\
\text { Approach }\end{array}$ & $\begin{array}{l}\text { MC\&A } \\
\text { Aspects }\end{array}$ & Benefits & Challenges & $\begin{array}{c}\text { Gaps in Current } \\
\text { Technology }\end{array}$ \\
\hline $\begin{array}{l}\text { Material balance } \\
\text { of inputs and } \\
\text { outputs to the } \\
\text { reactor }\end{array}$ & $\begin{array}{l}\text { - Thorough } \\
\text { accountancy } \\
\text { of inputs (i.e., } \\
\text { fresh fuel) and } \\
\text { outputs (i.e., } \\
\text { waste streams, } \\
\text { irradiated } \\
\text { nuclear fuel) } \\
\text { without a } \\
\text { focus on the } \\
\text { SNM in the } \\
\text { reactor itself } \\
\text { - Robust } \\
\text { containment } \\
\text { and } \\
\text { surveillance } \\
\text { within the } \\
\text { facility and } \\
\text { material } \\
\text { balance areas }\end{array}$ & $\begin{array}{l}\text { - Most similar to existing } \\
\text { LWR MC\&A approaches } \\
\text { - Would be relatively } \\
\text { straightforward to apply to } \\
\text { solid-fueled MSR designs, } \\
\text { as well as those with } \\
\text { liquid-fueled salt in } \\
\text { distinct assemblies }\end{array}$ & $\begin{array}{l}\text { - Would be more } \\
\text { difficult for liquid- } \\
\text { fueled designs with } \\
\text { online chemical } \\
\text { processing } \\
\text { - May have a large } \\
\text { inventory difference } \\
\text { (ID) that may require } \\
\text { further investigation } \\
\text { (e.g., quantification of } \\
\text { holdup) } \\
\text { - Measured outputs will } \\
\text { need to be compared } \\
\text { with predicted values of } \\
\text { fissile material } \\
\text { produced in the reactor; } \\
\text { models would be } \\
\text { affected by accuracies } \\
\text { of various inputs, } \\
\text { including cross-section } \\
\text { data }\end{array}$ & $\begin{array}{l}\text { - May require new or } \\
\text { modified } \\
\text { technologies to } \\
\text { quantify the SNM in } \\
\text { fresh fuel } \\
\text { salt/concentrate, } \\
\text { irradiated fuel salt, } \\
\text { and/or waste streams } \\
\text { - Models will need to } \\
\text { be developed, } \\
\text { verified, and } \\
\text { validated; some } \\
\text { designs (e.g., those } \\
\text { that operate in the } \\
\text { fast spectrum) may } \\
\text { need more accurate } \\
\text { nuclear physics data } \\
\text { (e.g., cross sections) } \\
\text { to achieve } \\
\text { reasonable } \\
\text { uncertainties }\end{array}$ \\
\hline $\begin{array}{l}\text { Material } \\
\text { accountancy } \\
\text { throughout the } \\
\text { process }\end{array}$ & $\begin{array}{l}\text { - Quantifies the } \\
\text { SNM } \\
\text { throughout the } \\
\text { process }\end{array}$ & $\begin{array}{l}\text { - Leverages existing data } \\
\text { tracked for the purposes of } \\
\text { safety analysis and } \\
\text { optimization of operations } \\
\text { - Potentially more timely } \\
\text { detection of SNM } \\
\text { diversion from the process } \\
\text { streams } \\
\text { - Likely more accurate in } \\
\text { determining location and } \\
\text { quantities of the SNM, } \\
\text { especially holdup and } \\
\text { other contributors to ID }\end{array}$ & $\begin{array}{l}\text { - Would require a revised } \\
\text { approach by the NRC } \\
\text { to use data from } \\
\text { "process monitoring" to } \\
\text { meet requirements in } \\
\text { SNM categories other } \\
\text { than Category I } \\
\text { - Would be costly to } \\
\text { integrate technologies if } \\
\text { measurements are not } \\
\text { already being taken for } \\
\text { other purposes }\end{array}$ & $\begin{array}{l}\text { - May require new or } \\
\text { modified } \\
\text { technologies to } \\
\text { quantify the SNM in } \\
\text { fresh fuel } \\
\text { salt/concentrate, } \\
\text { irradiated fuel salt, } \\
\text { and/or waste streams }\end{array}$ \\
\hline
\end{tabular}

Many liquid-fueled MSR designs with fuel dissolved in the salt will likely incorporate the ability for facility operators to monitor operational parameters to optimize operations and measure fuel salt thermochemical and thermophysical properties. This capability would help ensure that the parameters remain within the established limits necessary to satisfy the reactor safety bases or to perform fundamental safety functions. For example, one approach could be to extract a small quantity of salt from the reactor environment through a sampling line. Analysis of the sample material could allow determination of the quantities of fissile materials and actinide concentrations in near real time. Destructive analysis (i.e., mass spectrometry) techniques and/or in situ nondestructive analysis gamma and/or neutron detection systems could be used to determine the isotopic composition of the process stream(s). Much of this operational parameter data could provide relevant information to determine the material quantities and locations for MC\&A purposes. This methodology is often referred to in the technical community as "process monitoring." However, 10 CFR Part 74 uses that terminology in a very 
specific context associated with the robust MC\&A requirements mandatory for Category I, strategic SNM.

As described previously, vendors may submit license applications with appeals to exempt the SNM quantities that might traditionally be categorized as Category I, strategic SNM from those strict MC\&A requirements because diversion scenarios would be deemed noncredible based on high activities and/or physical-access constraints to that material. Applying the technical approach of material accountancy throughout the process streams would provide less overall uncertainty as to the location and quantities of the SNM within the facility. Additionally, the designs would likely already incorporate measurement systems to produce these data for nonsafeguards purposes. The NRC would benefit from more accurate and efficient MC\&A implementation at MSRs by encouraging the facility designers - especially those whose designs are liquid-fueled MSRs with fuel dissolved in salt - to incorporate the methodology of material accountancy throughout the process streams (i.e., process monitoring), while not necessarily requiring all of the obligations associated with the term "process monitoring" used in 10 CFR Part 74 for Category I SNM.

Additionally, vendors plan to market and operate their designs internationally. If constructed and/or operated in Non-Nuclear Weapon States, designers will need to incorporate international safeguards considerations to accommodate the need for the International Atomic Energy Agency (IAEA) to independently verify quantities and locations of fissile and fertile nuclear material into their designs. The IAEA has demonstrated that in facilities with large throughputs and the capability to separate out what the IAEA terms as "direct use nuclear material" (i.e., what is seen in MSR designs with liquid fuel dissolved in the salt and online chemical separation at the facility), it often implements online measurement systems to independently verify quantities of the material within the process streams ${ }^{10}$. Designers could potentially leverage access to these existing data to meet the NRC MC\&A requirements.

\section{MSR DESIGN FEATURES THAT ARE RELEVANT TO MC\&A}

MSR design features that are relevant from an MC\&A perspective are not necessarily the same features that are relevant from a performance or operations perspective. MC\&A objectives depend on the types, quantities, and locations of the SNM. Other design features will affect the ability to apply various safeguards measures (e.g., destructive or nondestructive measurements to quantify isotopes). This section identifies several design features that will impact the MC\&A approaches to meet domestic safeguards objectives. Because such diverse designs exist within the class of MSRs in different stages of development, representative design feature examples are referenced. The following design features will be relevant from an NRC MC\&A perspective ${ }^{11}$.

- Type of SNM: The element, isotope, and enrichment of the SNM determines the strategic significance of the SNM. The MC\&A requirements are defined by 10 CFR Part 74 for each category of SNM, although the NRC can exempt the SNM from requirements if diversion by theft is deemed noncredible for certain materials and/or locations.

- Physical and chemical form of SNM: The physical and chemical form of the SNM will affect the material attractiveness, which will impact the credibility of various diversion scenarios via theft. The

\footnotetext{
${ }^{10}$ For example, the IAEA uses process monitoring methodologies in its safeguards approach for Japan's Rokkasho reprocessing facility and its planned approach for the Republic of Korea's pyroprocessing facilities.

${ }^{11}$ This list is not comprehensive, but it does identify many of the categories of design features that may have a significant impact on how the design meets the NRC's MC\&A requirements, as defined in 10 CFR Part 74.
} 
physical and chemical form of the SNM will also influence the technologies and measurement equipment that can be used to quantify the SNM.

Radioactivity of material in which the SNM is located: The radioactivity of the material in which the SNM is located affects whether the diversion scenarios are credible. This could impact whether various MC\&A requirements are deemed necessary by the NRC. This will also affect what measurement systems can be used to produce MC\&A-relevant data.

- Concentration of SNM within the material: The volumetric concentration of the SNM within the material it is located (e.g., the SNM concentration in fresh fuel concentrate, the SNM concentration in fuel salt) will impact the total quantity of the material required to be diverted to obtain a quantity of strategic significance. This could affect whether various MC\&A requirements are deemed necessary by the NRC.

- Quantities of SNM: The quantities and types of the SNM categorize the strategic significance of the SNM. The throughput and quantities of the SNM used in the design will affect whether the quantities are too low to be of concern, such as if the uncertainties are within the statistical significance of the MC\&A requirements ${ }^{12}$.

- Accessibility of SNM: The physical accessibility of the SNM will impact whether diversion scenarios are credible. This could affect whether various MC\&A requirements are deemed necessary by the NRC. This will also impact what measurement systems can be used to produce MC\&A-relevant data.

\subsection{TYPES OF SNM}

Designers plan to use a diverse set of the SNM in MSR designs. The types and quantities of the SNM present will drive the categorization of the SNM's strategic significance and, therefore, the NRC's MC\&A requirements for that material. Additionally, the type and assay of the SNM will influence the technologies and equipment that are appropriate to measure the quantities of SNM within the material. Figure 1 depicts some of the different types of the SNM that are included in the existing MSR design concepts. Besides the SNM as defined by the NRC, additional fertile (e.g., ${ }^{232} \mathrm{Th}$, which may complicate some nondestructive or destructive measurement methodologies), fissile (e.g., Np, Am), and other (e.g., ${ }^{233} \mathrm{~Pa}$, a direct precursor to ${ }^{233} \mathrm{U}^{13}$ ) relevant materials are included.

\footnotetext{
1210 CFR Part 74 defines the quantities for which a report must be submitted to the NRC after a physical inventory. Currently unknown is whether uncertainties related to measurements, for example, the SNM quantities in irradiated salt, would be within those values.

${ }^{13}$ Some existing MSR designs, such as the Flibe Energy LFTR, include chemical separation of protactinium from the breeding salt loop. The ${ }^{233} \mathrm{~Pa} \beta^{-}$decays with a $100 \%$ probability, with a $t_{1 / 2}$ of 26.967 days.
} 


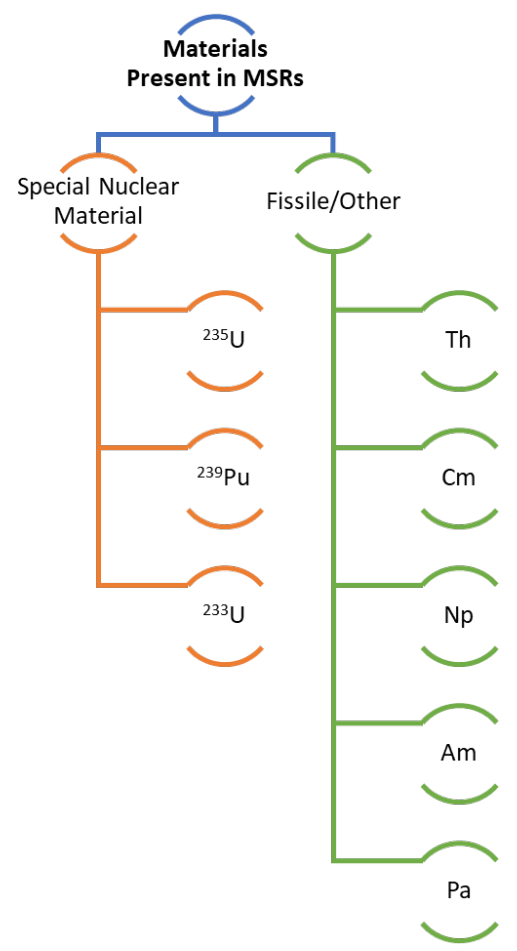

Figure 1. Types of SNM and other materials present in different MSR designs.

\subsection{CHEMICAL AND PHYSICAL FORM OF SNM}

The chemical and physical form of the SNM will drive the credibility of various diversion scenarios. The credibility of these scenarios will affect the determination of MC\&A requirements that the NRC deems appropriate for the specific MSR design. Figure 2 depicts different chemical and physical forms of the SNM in fresh fuel in the existing MSR designs.

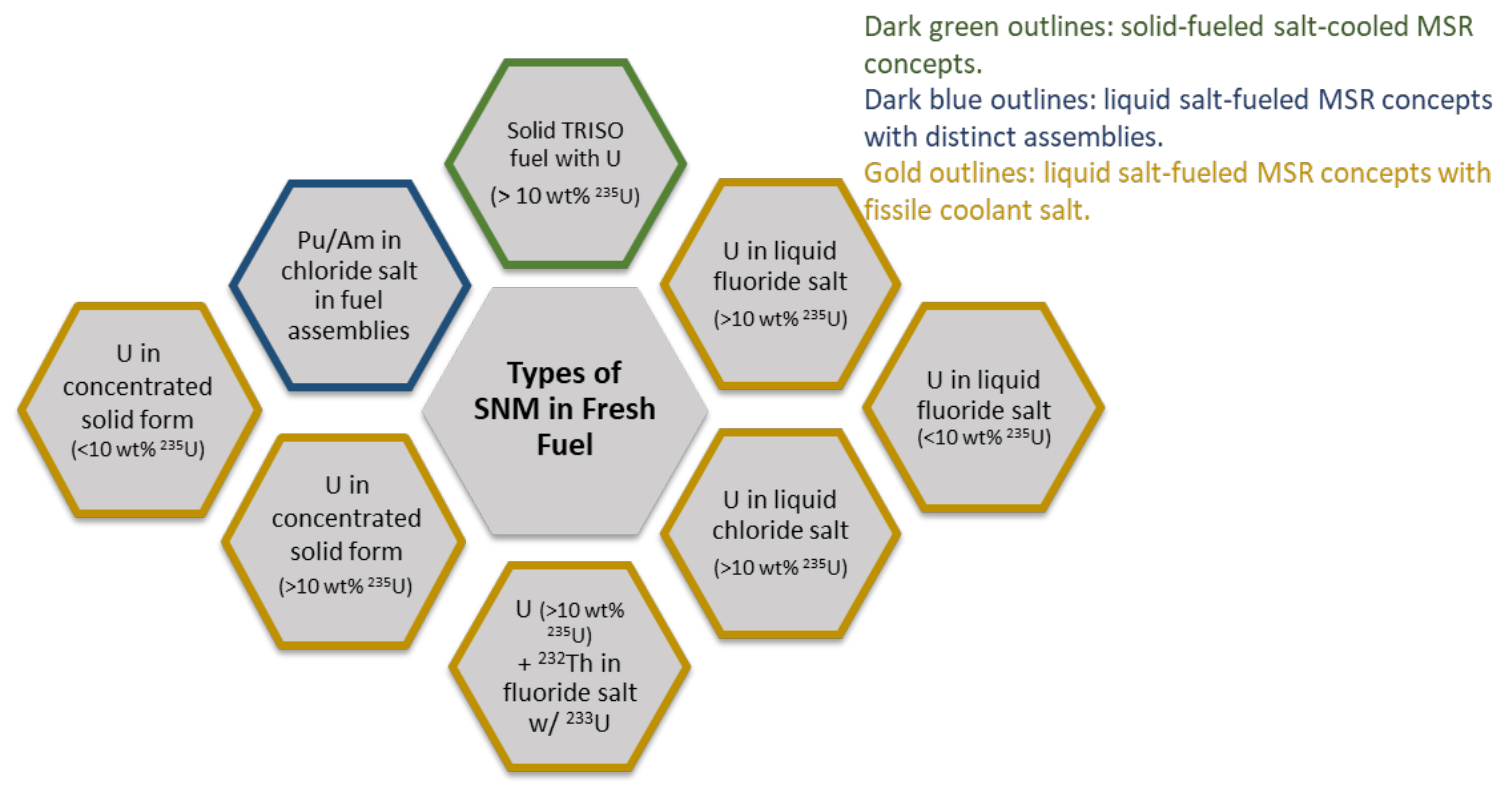

Figure 2. Physical and chemical forms of the SNM in fresh fuel in the MSR designs. 


\subsubsection{Radioactivity of material in which the SNM is located}

The radioactivity of the SNM will affect the credibility of diversion scenarios via theft, the types of measurements that can be taken to identify the quantities of the SNM, and the accuracies of those measurements. As with LWRs, MC\&A approaches will need to consider the high gamma and neutron environment of MSRs, once operational (Kovacic 2020). Accounting of fresh (i.e., unirradiated in the MSR) fuel (or fresh fuel concentrates) should present fewer challenges, as fresh fuel will be significantly less radioactive than irradiated fuels. Radioactivity levels of fresh fuel will be dependent on the composition of the fuel (e.g., whether it includes ${ }^{235} \mathrm{U}$, plutonium, or ${ }^{233} \mathrm{U}$ ), and the enrichment of those materials. Additionally, some MSR designs would use spent nuclear fuel (e.g., from a PHWR) as "fresh" fuel for the MSR. In this case, the fresh fuel would have higher radioactivity levels due to the presence of actinides and, potentially, fission products. MC\&A approaches might include in situ, nondestructive measurement systems, sampling lines to extract small amounts of material from the high gamma and neutron environment of the MSR for measurements, delayed measurements by letting a sample cool, and/or chemical separations of the salt to provide the sensitivity needed before analysis via mass spectrometry.

Currently, inadequate data exist on the anticipated activities of material within specific designs, but models are being developed that will allow estimations of dose rates in various environments.

\subsubsection{Concentration of SNM within the material}

The volumetric concentration of the SNM within the material will affect the credibility of diversion of material via theft, depending on the volumetric quantity of the material that would need to be diverted to obtain a quantity of strategic significance. Not only will the concentration of the SNM vary among SNM types in various designs but also within nuclear material strata within one facility design. For example, MSR designs that plan to use online fueling will likely have fresh fuel shipped and/or stored in a concentrated form. In some thorium fuel cycle designs, ${ }^{233} \mathrm{~Pa}$ (separated from a secondary breeding loop) will be stored in a decay tank in the chemical separation process before returning as fuel to the reactor. In these situations, the SNM concentration will likely be significantly higher than the SNM concentration in, for example, a fissile salt loop circulating throughout the reactor.

\subsection{QUANTITIES OF SNM}

Data on the quantities of the SNM planned to be used in various designs are not yet publicly available. However, relevant to the NRC's criteria to categorize SNM based on its strategic significance, the following issues are likely:

- In some thorium fuel cycle liquid-fueled MSR designs with online chemical separation, greater than $2 \mathrm{~kg}$ of separated ${ }^{233} \mathrm{U}$ will be in a decay tank (Uribe, et al. 2020).

- In solid-fuel MSR designs using TRISO fuel pebbles, the irradiated pebbles in total will accumulate greater than $2 \mathrm{~kg}$ of plutonium, with an estimated less than $1 \mathrm{~g}$ of plutonium per pebble or fuel compact (Kovacik, Gibbs and Scott 2020).

- In liquid-fueled MSR designs with distinct fuel assemblies, the salt within the assemblies will accumulate greater than $2 \mathrm{~kg}$ of plutonium.

- In several commercial MSR designs that plan to use uranium enriched greater than $10 \%$, greater than $10 \mathrm{~kg}$ of ${ }^{235} \mathrm{U}$ will exist. 


\subsection{ACCESSIBILITY OF SNM}

The accessibility of SNM will affect the MC\&A approaches in a similar way to the activity of the SNM. The activity of the SNM also impacts how accessible the SNM is. In the solid fuel designs, once the fuel is in the reactor the accessibility would be similar to that of an LWR. However, many liquid-fueled designs incorporate online refueling, which may make the fuel more accessible for potential diversion. Additionally, some liquid-fueled MSR designs with fissile material in coolant salt may receive fresh fuel in a concentrated form. The SNM in fresh fuel that arrives or is stored onsite (outside of the reactor containment) may require additional MC\&A considerations because of its accessibility and low dose rates. Additionally, the SNM separated onsite in a chemical separation process, as is included in some liquid-fueled designs, may also need additional considerations.

\section{POTENTIAL MC\&A CHALLENGES AND RECOMMENDATIONS}

Overall, the SNM in many MSR designs will likely meet the NRC criteria to be categorized as Category I, strategic SNM. However, in many of these designs, the theft of this material may be deemed to be noncredible based on the high dose rates of the SNM if combined with fission products and actinides in a single fuel salt or in solid fuel. It may be reasonable for the NRC to grant exceptions, in accordance with 10 CFR Part 74.7, from the Category I (or even Category II) MC\&A requirements in 10 CFR Part 74 for MSR designs with solid fuel and salt coolant and liquid fuel dissolved into the salt in a single operating loop (i.e., no separate breeder loop) with no onsite chemical separation because diversion scenarios via theft are unlikely. MSR designs that include chemical separation of fissile material (i.e., ${ }^{233} \mathrm{U}$ in some thorium fuel-cycle MSR designs, or ${ }^{235} \mathrm{U}$ or ${ }^{239} \mathrm{Pu}$ in theoretical future designs) to recycle as the fuel may require additional considerations. In liquid-fueled MSR concepts with fissile material in the salt, many designs will likely already incorporate technologies to monitor the composition of the fuel salt. The NRC would likely benefit from adapting its current approach to process monitoring to allow for data obtained from measurements within the process stream to be used more broadly (i.e., not just to meet the specific requirements for Category I SNM) to give confidence that nuclear material has not been diverted from any of the process streams.

Another challenge with MSR designs will be adjusting physical inventories to a facility with ongoing dynamic operations in liquid-fueled MSRs with fuel dissolved in the coolant salt. These facilities will have scheduled shutdowns, but not for refueling like LWRs. Because of the corrosive nature of salts, core and reactor system components that are wetted with the salt will have a limited lifetime. Designers and the NRC may choose to approach physical inventories in these facilities with a methodology similar to enrichment plants, where inventories are done in a facility under continuous operations with no cleanout or shutdown. Complete inventories with the cleanout of the SNM in the process streams and equipment and quantification of residual nuclear material could be done during periodic shutdowns of the facility, including shutdowns where components damaged by corrosion are replaced. There will likely be significant MC\&A challenges associated with effectively and efficiently quantifying the SNM for MC\&A purposes during these scheduled shutdowns, especially when fissile material dissolved in coolant salt is drained from systems. During these time periods, the SNM from the system will be put into different tanks or containers and potentially moved into a different material balance area. Unlike LWR shutdowns, where the SNM remains in large, heavy, highly radioactive "item" form, some SNM in liquid-fueled MSRs where fuel is dissolved in coolant salt will likely remain in the system components (e.g., as a result of plating out) and the SNM from some emptied process streams may be significantly more accessible than the SNM in the LWR fuel assemblies. The NRC would benefit from early discussions with designers as to how SNM will be controlled and accounted for in systems during these maintenance periods. 
If the MSR designs are constructed, the SNM will have to be quantified in chemical, physical, and isotopic forms that introduce new MC\&A challenges for the NRC. Some of these forms that are new to commercial scale include

- the SNM, especially uranium enriched to greater than $10 \%$ in ${ }^{235} \mathrm{U}$, in fuel salt concentrates (i.e., fresh fuel for liquid-fueled designs with on-line refueling);

- $\quad{ }^{233} \mathrm{U}$ in process streams within designs with onsite chemical separations;

- the SNM in waste streams (e.g., irradiated fuel in once-through systems before shipment off-site, small amounts of the SNM in process streams such as off-gas systems or fission-product streams); and

- the residual SNM that remains in equipment or components after shutdown at the end of the lifecycle of components in liquid-fueled MSRs where fuel is dissolved into the coolant salt ${ }^{14}$.

Whether existing technologies can be leveraged and provide results with uncertainties within those required in 10 CFR Part 74 is currently unknown.

When engaging with vendors while considering MC\&A, the NRC may want to focus questions on the design and its features included in Section 3. With that information, the NRC may begin to assess the strategic significance of the SNM in the design and whether any diversion scenarios via theft are credible. Any remaining credible diversion scenarios could be addressed by modifying the design, adding securityrelated features to make access to the SNM noncredible, or integrating in situ measurement systems to obtain accurate data on quantities of the SNM. In this situation, the NRC may want to consider what data may already be available for purposes of fuel qualification or optimization of operations. Leveraging that data to meet MC\&A requirements would require flexibility from the NRC to broaden the interpretation of the term "process monitoring" used in 10 CFR Part 74.

\footnotetext{
${ }^{14}$ Note that this will be before the end of the operating life of the reactor facility. Due to the corrosive salt, reactor components will need to be replaced at periodic intervals throughout the lifetime of the core. These intervals will be shorter than those for LWRs, and the SNM will likely have plated out and remain in some of the components.
} 


\section{REFERENCES}

Flibe Energy. 2020. Flibe Energy. Accessed November 2020. https:/flibe-energy.com/.

Hongjie, XU. 2017. "Status and Perspective of TMSR in China." Gen IV International Forum. January 24, 2017. https://www.gen-4.org/gif/upload/docs/application/pdf/201705/03_hongjie_xu_china.pdf.

Kairos Power. 2020. Kairos Power: Technology. Accessed December 2020. https://kairospower.com/technology/.

Kovacic, et al. 2020. Advanced Reactor Safeguards: Nuclear Material Control and Accounting for Pebble Bed Reactors, ORNL/SPR-2020/1849.

Kovacic, Donald, Philip Gibbs, and Logan Scott. 2020. MC\&A Program Performance Assessments for Pebble Bed Reactors. ORNL/SPR-2019/1329.

Nuclear Regulatory Commission. 2017. Safeguard Categories of SNM. Accessed November 2020. https://www.nrc.gov/security/domestic/mca/snm.html.

Scott, Ian. 2020. "Stable Salt Reactors: A New Platform Technology in Nuclear Fission." Moltex Energy Ltd. October 15, 2020. https://msrworkshop.ornl.gov/wpcontent/uploads/2020/11/24_Scott_Moltex_SSR_ORNL1.pdf.

TerraPower. 2020. Molten Chloride Fast Reactor Technology. Accessed December 2020. https://www.terrapower.com/our-work/molten-chloride-fast-reactor-technology/.

Terrestrial Energy. 2020. IMSR ${ }^{\circledR}$ : Transformative Clean Energy Technology. Accessed December 2020. https://www.terrestrialenergy.com/.

ThorCon. 2020. Accessed December 2020. http://thorconpower.com/.

Uribe, Eva, S. Matt Gilbert, Louise Worrall, Nicholas Luciano, Richard Reed, Natalie McGirl, and Jeffrey Powers. 2020. Quantification of Protactinium Production in Thorium Fuel Cycles. Manuscript submitted for publication, Sandia National Laboratories. 